\title{
ENERGI TOTAL KEADAAN EKSITASI ATOM LITIUM DENGAN METODE VARIASI
}

\author{
LIU KIN MEN* DAN SETIANTO \\ Departemen Fisika Fakultas MIPA Universitas Padjadjaran, \\ Jl. Raya Bandung-Sumedang Km 21, Jatinangor 45363 \\ *email :liu@phys.unpad.ac.id
}

\begin{abstract}
Abstrak. Atom Litium adalah suatu atom yang mempunyai 3 buah elektron pada kulitnya. Pada keadaan eksitasi, satu elektron menduduki orbital 1s dan dua elektron lainnya menduduki orbital 2s. Fungsi gelombang total keadaan eksitasi ditentukan melalui ekspansi determinan Slater. Hamiltonian total merupakan gabungan dari Hamiltonian masing-masing elektron dan suku interaksi di antara ketiga elektron bersangkutan. Dengan diperolehnya fungsi gelombang total dan Hamiltonian total, maka energi total keadaan eksitasi atom Litium dapat ditentukan. Perhitungan dilakukan dengan metode variasi dan diperoleh $\mathrm{E}=-135,5007 \mathrm{eV}$.
\end{abstract}

Kata kunci : Atom Litium, keadaan eksitasi, metode variasi

\begin{abstract}
Lithium atom is an atom that has three electrons in the shell. In the excited state, one electron occupying the $1 \mathrm{~s}$ orbital and two other electron occupying the $2 \mathrm{~s}$ orbital. Total wave function of excitation is determined through the expansion of Slater determinants. Total Hamiltonian is a combination of each electron Hamiltonian and the interaction term between the three electrons. By obtaining the total wave function and total Hamiltonian, then the total energy of Lithium atom excitation state can be determined. Calculations performed by the method of variation and obtained by $\mathrm{E}=-$ $135.5007 \mathrm{eV}$.
\end{abstract}

Keywords : Lithium atom ,excited state, method of variation

\section{Pendahuluan}

Dalam teori kuantum atom Hidrogen yaitu suatu atom yang hanya mempunyai satu elektron pada kulitnya, melalui persamaan Schrodinger diperoleh fungsifungsi gelombang (orbital-orbital) elektron dan energi-energi yang bersangkutan [1]. Hasil-hasil ini selanjutnya dipergunakan sebagai basis untuk menggambarkan atom-atom dengan sejumlah elektron, khususnya berkaitan dengan energi total keadaan dasar dan energi total keadaan eksitasi [2]. Untuk energi total keadaan dasar, penentuan telah dilakukan pada atom Litium [3] dan atom Berilium [4]. Agar penyelesaian cukup sederhana dan lebih memadai, perhitungan energi total keadaan eksitasi dilakukan pada atom Litium dan menggunakan metode variasi.

\section{Metode Eksperimen}

\subsection{Teori Kuantum Atom Litium}

Teori kuantum atom Litium tidak diturunkan secara langsung melalui persamaan Schrodinger. Tingkat-tingkat energi dan fungsi-fungsi gelombangnya didasarkan 
pada atom Hidrogen. Litium adalah suatu contoh dari atom-atom dengan banyak elektron.

Fungsi gelombang total keadaan dasar dari atom dengan banyak elektron ( $\mathrm{N}$ elektron ) diungkapkan oleh determinan Slater yaitu:

$\Psi_{0}=\frac{1}{\sqrt{N !}}\left|\begin{array}{cccc}\varphi_{1}(1) \alpha(1) & \varphi_{1}(1) \beta(1) & \ldots & \varphi_{N / 2}(1) \beta(1) \\ \varphi_{1}(2) \alpha(2) & \varphi_{1}(2) \beta(2) & \ldots & \varphi_{N / 2}(2) \beta(2) \\ \ldots & \ldots & \ldots & \ldots \\ \varphi_{1}(N) \alpha(N) & \varphi_{1}(N) \beta(N) & \ldots & \varphi_{N / 2}(N) \beta(N)\end{array}\right|$,

sedangkan Hamiltonian totalnya adalah

$\widehat{H}=\sum_{i}\left(H_{i}+\frac{1}{2} \sum_{j \neq i} \frac{e^{2}}{4 \pi \epsilon_{0} r_{i j}}\right)$.

Dalam hal ini $\varphi_{1}(1) \alpha(1)$ menyatakan orbital 1 yang diduduki oleh elektron 1 dan mempunyai spin $\alpha$, dan dengan cara yang sama berarti suku yang terakhir $\varphi_{N / 2}(N) \beta(N)$ menyatakan orbital $\mathrm{N} / 2$ yang diduduki oleh elektron $\mathrm{N}$ dan mempunyai spin $\beta$. Selanjutnya $e$ adalah muatan elektron, $\epsilon_{0}$ adalah permitivitas ruang hampa, $r_{i j}$ adalah jarak antara elektron ke $-i$ dan elektron ke $-j$, karena itu suku kedua sebelah kanan dari persamaan adalah potensial interaksi di antara elektron-elektron, dan

$H_{i}=-\frac{\hbar^{2}}{2 m} \nabla_{i}^{2}-\frac{\zeta e^{2}}{4 \pi \epsilon_{0} r_{i}}$

adalah Hamiltonian dari elektron tunggal.

Untuk keadaan eksitasi, fungsi gelombang totalnya ditentukan melalui ekspansi determinan Slater sedangkan Hamiltoniannya adalah sama seperti Hamiltonian pada keadaan dasar. Karena ituuntuk atom Litium pada keadaan eksitasi ( terdiri dari 3 buah elektron, 1 elektron menduduki orbital 1 s dan 2 elektron menduduki orbital $2 \mathrm{~s}$ ), fungsi gelombang totalnya adalah:

$\Psi^{\prime}=\frac{1}{\sqrt{6}}\left|\begin{array}{lll}\varphi_{1 s}(1) \alpha(1) & \varphi_{2 s}(1) \alpha(1) & \varphi_{2 s}(1) \beta(1) \\ \varphi_{1 s}(2) \alpha(2) & \varphi_{2 s}(2) \alpha(2) & \varphi_{2 s}(2) \beta(2) \\ \varphi_{1 s}(3) \alpha(3) & \varphi_{2 s}(3) \alpha(3) & \varphi_{2 s}(3) \beta(3)\end{array}\right|$,

sedangkan Hamiltoniannya adalah

$\widehat{H}=H_{1}+H_{2}+H_{3}+\frac{e^{2}}{4 \pi \epsilon_{0} r_{12}}+\frac{e^{2}}{4 \pi \epsilon_{0} r_{13}}+\frac{e^{2}}{4 \pi \epsilon_{0} r_{23}}$.

\subsection{Metode Variasi}

Dalam metode variasi, energi total keadaan eksitasi ditentukan berdasarkan hubungan. 
$E=\left\langle\Psi^{\prime}|\widehat{H}| \Psi^{\prime}\right\rangle$

dalam hal ini $\Psi^{\prime}$ adalah fungsi gelombang total keadaan eksitasi dan $\widehat{H}$ adalah Hamiltonian total dari sistem yang bersangkutan. Di sini $\Psi^{\prime}$ tersusun oleh orbitalorbital atom yang mengandung parameter variasi $\zeta$. Energi minimum akan diperoleh jika

$\frac{\partial E}{\partial \zeta}=0$.

Dari sini akan diperoleh parameter $\zeta$ sehingga diperoleh juga $E$.

\section{Hasil dan Pembahasan}

Berdasarkan fungsi gelombang total dan Hamiltonian total yang telah dituliskan pada bagian sebelumnya, diperoleh energi total keadaan eksitasi adalah :

$E=E_{1 s}+2 E_{2 s}+2 J_{12}+J_{22}-K_{12}$,

dalam hal ini

$$
\begin{aligned}
E_{1 s} & =<\varphi_{1 s}(1)\left|H_{1}\right| \varphi_{1 s}(1)>=<\varphi_{1 s}(2)\left|H_{2}\right| \varphi_{1 s}(2)>=<\varphi_{1 s}(3)\left|H_{3}\right| \varphi_{1 s}(3)> \\
E_{2 s} & =<\varphi_{2 s}(1)\left|H_{1}\right| \varphi_{2 s}(1)>=<\varphi_{2 s}(2)\left|H_{2}\right| \varphi_{2 s}(2)>=<\varphi_{2 s}(3)\left|H_{3}\right| \varphi_{2 s}(3)> \\
J_{12} & =<\varphi_{1 s}(1) \varphi_{2 s}(2)\left|\frac{e^{2}}{4 \pi \epsilon_{0} r_{12}}\right| \varphi_{1 s}(1) \varphi_{2 s}(2)> \\
& =<\varphi_{1 s}(1) \varphi_{2 s}(3)\left|\frac{e^{2}}{4 \pi \epsilon_{0} r_{13}}\right| \varphi_{1 s}(1) \varphi_{2 s}(3)> \\
& =<\varphi_{1 s}(2) \varphi_{2 s}(3)\left|\frac{e^{2}}{4 \pi \epsilon_{0} r_{23}}\right| \varphi_{1 s}(2) \varphi_{2 s}(3)>
\end{aligned}
$$

$$
\begin{aligned}
J_{22} & =<\varphi_{2 s}(1) \varphi_{2 s}(2)\left|\frac{e^{2}}{4 \pi \epsilon_{0} r_{12}}\right| \varphi_{2 s}(1) \varphi_{2 s}(2)> \\
& =<\varphi_{2 s}(1) \varphi_{2 s}(3)\left|\frac{e^{2}}{4 \pi \epsilon_{0} r_{13}}\right| \varphi_{2 s}(1) \varphi_{2 s}(3)> \\
& =<\varphi_{2 s}(2) \varphi_{2 s}(3)\left|\frac{e^{2}}{4 \pi \epsilon_{0} r_{23}}\right| \varphi_{2 s}(2) \varphi_{2 s}(3)>
\end{aligned}
$$




$$
\begin{aligned}
K_{12} & =<\varphi_{1 s}(1) \varphi_{2 s}(2)\left|\frac{e^{2}}{4 \pi \epsilon_{0} r_{12}}\right| \varphi_{2 s}(1) \varphi_{1 s}(2)> \\
& =<\varphi_{1 s}(1) \varphi_{2 s}(3)\left|\frac{e^{2}}{4 \pi \epsilon_{0} r_{13}}\right| \varphi_{2 s}(1) \varphi_{1 s}(3)> \\
& =<\varphi_{1 s}(2) \varphi_{2 s}(3)\left|\frac{e^{2}}{4 \pi \epsilon_{0} r_{23}}\right| \varphi_{2 s}(2) \varphi_{1 s}(3)>.
\end{aligned}
$$

Dengan substitusi

$\varphi_{1 s}=\frac{1}{\sqrt{\pi}}\left(\frac{\zeta}{a_{0}}\right)^{\frac{3}{2}} e^{-\zeta r / a_{0}}$

$\varphi_{2 s}=\frac{1}{4 \sqrt{2 \pi}}\left(\frac{\zeta}{a_{0}}\right)^{\frac{3}{2}}\left(2-\frac{\zeta r}{a_{0}}\right) e^{-\zeta r / 2 a_{0}}$,

diperoleh

$$
\begin{aligned}
& E_{1 s}=-\frac{e^{2}}{4 \pi \epsilon_{0} a_{0}}\left[\frac{\zeta^{2}}{2}+(3-\zeta) \zeta\right] \\
& E_{2 s}=-\frac{e^{2}}{4 \pi \epsilon_{0} a_{0}}\left[\frac{1}{8} \zeta^{2}+\frac{1}{4}(3-\zeta) \zeta\right] \\
& J_{12}=\frac{e^{2}}{4 \pi \epsilon_{0} a_{0}} \frac{17}{81} \zeta \\
& J_{22}=\frac{e^{2}}{4 \pi \epsilon_{0} a_{0}} \frac{121}{512} \zeta \\
& K_{12}=\frac{e^{2}}{4 \pi \epsilon_{0} a_{0}} \frac{16}{729} \zeta .
\end{aligned}
$$

Dengan demikian diperoleh

$$
E=-\frac{e^{2}}{8 \pi \epsilon_{0} a_{0}}\left[-\frac{3}{2} \zeta^{2}+7,73174 \zeta\right] .
$$

Energi minimum memberikan

$\frac{\partial E}{\partial \zeta}=0$

sehingga

$\zeta=2,5772$. 
Sebagai akibatnya energi total keadaan eksitasi atom Litium adalah

$E=-135,5007 \mathrm{eV}$

\section{Kesimpulan}

Telah dilakukan perhitungan energi total keadaan eksitasi atom Litium dengan metode variasi dan diperoleh $E=-135,5007 \mathrm{eV}$. Suku interaksi antar elektron memberikan kontribusi yang cukup besar bagi energi total.

\section{Ucapan terima kasih}

Penulis menyampaikan terima kasih kepada sdr. Haeruman dan sdr. Muhammad Rizqan Akbar atas diskusi-diskusi dalam penyelesaian tulisan ini.

\section{Daftar Pustaka}

1. Siregar, R. E. , Fisika Kuantum, Widya Padjadjaran, 2010.

2. Siregar, R. E. , Struktur Elektronik Atom dan Molekul, Diktat, 2014.

3. Liu, K. M. , Energi Total Keadaan Dasar Atom Litium dengan Metode Variasi, Laporan Penelitian Mandiri, Tidak Dipublikasikan, 2014.

4. Liu, K. M. , Energi Total Keadaan Dasar Atom Berilium dengan Metode Variasi, Laporan Penelitian Mandiri, Tidak Dipublikasikan, 2016. 